\title{
Knockdown BMI1 expression inhibits proliferation and invasion in human bladder cancer T24 cells
}

\author{
Wu Liang $\cdot$ Dingjun Zhu $\cdot$ Xuejiang Cui $\cdot$ \\ Jiarui Su $\cdot$ Hongwei Liu $\cdot$ Jinli Han • \\ Fengjin Zhao $\cdot$ Wenlian Xie
}

Received: 5 March 2013/ Accepted: 19 June 2013/Published online: 3 July 2013

(C) The Author(s) 2013. This article is published with open access at Springerlink.com

\begin{abstract}
B cell-specific moloney murine leukemia virus integration site 1 (BMI1) is a transcriptional repressor of polycomb repressive complex 1 , which is involved in the proliferation, senescence, migration, and tumorigenesis of cancer. Experimental researchers have convincingly linked BMI1 to tumorigenesis. However, there is no study about the issue on the role of BMI1 in the proliferation, apoptosis, and migration of bladder cancer. To address this question, we examined the expression of BMI1 in bladder cancer tissues and used siRNA to knockdown BMI1 expression in bladder cancer T24 cells. Then we tested the cell proliferation by CCK8 assay and soft agar colony formation assay, apoptosis by flow cytometry assay, and cell invasiveness by transwell migration assay. Our results revealed that BMI1 promoted proliferation, migration, invasion, and progression in bladder cancer. Over-expression of BMI1 was correlated with tumor clinic-pathological features. BMI1 siRNA effectively inhibited bladder cancer cell proliferation and migration in vitro, and it promoted bladder cancer
\end{abstract}

Electronic supplementary material The online version of this article (doi:10.1007/s11010-013-1745-0) contains supplementary material, which is available to authorized users.

W. Liang $\cdot$ D. Zhu $\cdot$ X. Cui $\cdot$ J. Su $\cdot$ J. Han .

F. Zhao - W. Xie $(\square)$

Department of Urology, The Second Affiliated Hospital of Sun

Yat-sen University, No. 107 Yan-jiang West Road, Guangzhou,

Guangdong Province 510120, People's Republic of China

e-mail: wenlianxie@ sina.com

W. Liang

e-mail: doctorliangwu@sina.com

H. Liu

Department of Urology, The Affiliated Hospital of Guangdong

Medical College, Zhan-jiang, Guangdong Province,

People's Republic of China invasion, maybe by causing epithelial-to-mesenchymal transition. Our findings suggested that BMI1 may represent a novel diagnostic marker and a therapeutic target for bladder cancer, and deserves further investigation.

Keywords BMI1 - Bladder cancer - Invasion · Proliferation · EMT

\section{Introduction}

Bladder cancer is a frequent urological malignancy cancer and accounts for about $3 \%$ of all cancer related deaths. In spite of recent progress in its diagnosis and treatment, the molecular mechanisms underlying the development and progression of bladder cancer remain poorly understood, and prognosis of invasive bladder cancer still remains unsatisfactory [1]. Therefore, it is of great urgent to further investigate the molecular mechanisms of bladder cancer metastasis and progression, which will improve the prognosis of invasive bladder cancer.

B-cell-specific moloney murine leukemia virus integration site 1 (BMI1) is a transcriptional repressor of polycomb repressive complex 1 (PRC1), which is located at chromosome 10p11.23. It plays an essential role in embryogenesis and maintenance adult stem cell's selfrenewal [2, 3]. BMI1 was originally identified as an oncogene which was associated with c-myc in the generation and development of mouse pre B-cell lymphomas [4]. There is a body of evidences suggesting that BMI1 is involved in the proliferation, senescence, migration, and tumorigenesis of cancer [5-9]. Experimental researchers have convincingly linked BMI1 to tumorigenesis. High expression of BMI1 was associated with aggressive tumor behavior and poor outcome [10]. 
High expression of BMI1 has been shown to be associated with poor prognosis in bladder cancer [11]. However, the mechanisms of how BMI1 functions to promote bladder cancer progress remain elusive. Because of the significance of BMI1 in cancers tumorigenesis, we hypothesis it may play an important role in bladder cancer tumorigenesis and metastasis. In this study, we investigated the effects of BMI1 knockdown on the proliferation, apoptosis, and invasive in bladder cancer T24 cells. And we found that BMI1 knockdown effectively inhibited bladder cancer T24 cells proliferation and migration in vitro, and it promoted bladder cancer invasion, maybe by causing epithelial-to-mesenchymal transition (EMT).

\section{Materials and methods}

Patients and samples

To investigate the protein expression, a retrospective review of formalin-fixed, paraffin-embedded tissue sections from 71 patients who underwent transurethral resection, or radical cystectomy, was conducted. Thirty-five normal tissue sections were obtained from the 71 patients at the same time to act as control samples. The protocol for the study was approved by the institutional review board of Sun Yat-sen University. The characteristics of the 71 patients are depicted in Table 1. The use of tumor samples was prospectively approved by the ethics committee of Sun Yat-sen University. Informed consent was obtained from all of the patients.

All patients' histopathological parameters were evaluated according to the 2002 TNM classification of the International Union Against Cancer (UICC) and the International Society of Urological Pathologists (ISUP) consensus classification of urothelial neoplasms of the urinary bladder, which is equivalent to the $2004 \mathrm{WHO}$ grading system.

\section{Cell culture}

Bladder cancer T24 cell was bought from ATCC, and cultured in a humidified $\mathrm{CO}_{2}$ incubator at $37{ }^{\circ} \mathrm{C}$ in RPMI 1640 (GIBCO), supplemented with $10 \%$ fetal bovine serum and $1 \%$ Penicillin-Streptomycin (Invitrogen).

Immunohistochemical analysis

$4 \mu \mathrm{m}$ formalin-fixed, paraffin-embedded tissue sections were deparaffinized with xylene, rehydrated in serial dilution of ethanol, and boiled (microwave) for $15 \mathrm{~min}$ for antigen retrieval in EDTA buffer ( $\mathrm{pH}$ 8.0) for BMI1. The sections were then incubated with $3 \%$ hydrogen peroxide for $10 \mathrm{~min}$ to quench endogenous peroxidase activity,
Table 1 Characteristics of archival paraffin-embedded specimens

\begin{tabular}{ll}
\hline Adjacent non-cancerous specimens number & 35 \\
Age, years & \\
Range & $39-83$ \\
Mean & $65.37 \pm 9.69$ \\
Gender & \\
Male & $30(85.7)$ \\
Female & $5(14.3)$ \\
Cancerous specimens number & 71 \\
Age, years & \\
Range & $34-83$ \\
Mean & $62.6 \pm 10.14$ \\
Gender & \\
Male & $61(85.9)$ \\
Female & $10(14.1)$ \\
Clinical stage & \\
Superficial $\left(\mathrm{T}_{\mathrm{a}}-\mathrm{T}_{1}\right)$ & $44(62.0)$ \\
Invasive $\left(\mathrm{T}_{2}-\mathrm{T}_{4}\right)$ & $27(38.0)$ \\
Pathological grade & \\
$\mathrm{G}_{1}$ & $19(26.8)$ \\
$\mathrm{G}_{2}$ & $37(52.1)$ \\
$\mathrm{G}_{3}$ & $15(21.1)$ \\
\hline Varing &
\end{tabular}

Values in parentheses are percents

followed by incubation with goat serum to block nonspecific binding. Slides were washed with PBS and incubated with monoclonal anti-BMI1 antibody (05-637, 1:50, Upstate Biotechnology, Lake Placid, USA) for $1 \mathrm{~h}$ at room temperature. They were subsequently reacted with biotinylated secondary antibody for $10 \mathrm{~min}$, followed by incubation with streptavidin-horseradish-peroxidase complex. After further washing, 3,3'-diaminobenzidine (DAB) was applied to the slides as a substrate. Sections were counterstained with Mayer's hematoxylin, dehydrated with ascending concentrations of alcohol, and mounted by crystal mount. As negative controls, the primary antibody was replaced with non-immune $\operatorname{IgG}$ of the same isotype.

The immunohistochemistry scoring was performed by two independent observers. Only nuclear staining was considered positive. Immunoreactivity was classified semiquantitatively into four categories based on the intensity of staining and the proportion of tumor cells showing unequivocal positive reaction. A staining index (SI) was calculated as a product of staining intensity and area of positive tumor cell nuclei $(1,0-10 \%$ positive cells; 2 , 10-50 \% positive cells with weak staining intensity; 3 , $>50 \%$ positive cells with moderate staining intensity; 4 , $>50 \%$ positive cells with strong staining intensity). In subsequent statistical analyses, the cutoff was based on median $\operatorname{SI}(<3$ vs. $\geq 3)$, after considering the frequency distribution curve and size of subgroups. 


\section{Western blot}

Briefly, 20ug of Proteins were separated by SDS-PAGE, and transferred to polyvinylidene difluoride (PVDF) membranes (Millipore, Bedford, Massachusetts, USA). membranes were blocked and then probed with antibodies against BMI1 (05-637, 1:150, Upstate Biotechnology, Lake Placid, USA), P16 (BA0266, 1:150, Boster Biological Technology, Wuhan, China), P14 (bs-1174R, 1:250, Bioss Biotechnology, Beijing, China), CDK2 (1:500, abcam), cyclin D1 (1:400, abcam), caspase 3 (1:500, abcam), Bcl$2(1: 100$, abcam), $\beta$-actin (1:1000, abcam), GAPDH (1:1000, abcam). The blots were then washed with trisbuffered saline/tween-20 solution and were incubated with horseradish peroxidase-conjugated goat anti-rabbit $\operatorname{IgG}$ (1:5000, Santa cru biotechnology) or goat anti-mouse IgG (1:5000, Santa cru biotechnology) at room temperature. After washed, the blots were exposed using a chemiluminescent detection system (Amersham Life Science, Buckinghamshire, UK).

\section{BMI1 siRNA and control siRNA transfection}

The on-target plus BMI1 pool siRNA and non-targeting control siRNA used for knockdown BMI1 expression were purchased from Santa Cruz Co (sc-29814, California, USA). It is a pool of 3 target-specific 19-25 nt siRNA designed to knock down gene expression [12-14]. They were transfected in T24 cells at a concentration of $100 \mathrm{~nm}$, respectively. T24 cells were cultured at $37{ }^{\circ} \mathrm{C}$ in a $\mathrm{CO}_{2}$ incubator until the cells were $60-80 \%$ confluent. Subsequently, the cells were transfected with Lipofectamine TM2000 (Invitrogen) according to the manufacturer's instructions. The transfection reagent $(10 \mu \mathrm{l})$ and BMI1 siRNA or control siRNA (6 $\mu \mathrm{l}$ each) were incubated with T24 cells in RPMI-1640 culture (serum-free media) for $6 \mathrm{~h}$, and then complete media were used to culture for, a further $48 \mathrm{~h}$, the experiments as described.

\section{CCK-8 for proliferation assay}

Cell proliferation was assessed using WST-8 dye (Beyotime institute of biotechnology, China), according to the manufacturer's instructions/protocol. Briefly, 5,000 T24 cells/wells were seeded in a 96-well cell culture plate, grown at $37{ }^{\circ} \mathrm{C}$ for $24 \mathrm{~h}$, and then placed in serum-started condition for another $6 \mathrm{~h}$. Subsequently, T24 cells were transfected with BMI1 siRNA and control siRNA, respectively. On the day of measuring the growth rate of untreated and transfected cells, $100 \mu \mathrm{l}$ of spent medium was replaced with an equal volume of fresh medium containing $10 \% \mathrm{CCK} 8$, then cells continued to be incubated at
$37{ }^{\circ} \mathrm{C}$ for $3 \mathrm{~h}$, and the absorbance was finally determined at $450 \mathrm{~nm}$ using a micro plate reader.

Soft agar colony formation assay

Briefly, 6-well plates were coated with a bottom layer of $1.5 \mathrm{ml}$ base agar consisting of $0.5 \%$ agar, 1 *RPMI 1640 medium, and $10 \%$ fetal bovine serum, followed by a top layer of $1 \mathrm{ml} 0.35 \%$ agar. In each well, 5000 cells were plated over the top layer. Each assay was performed in triplicate wells. Plates were assessed for number and size of colonies under a microscope after 3 weeks of incubation. All experiments were performed three times.

Flow cytometry assay

After infection treatment, cells in each well were harvested, and cell apoptosis was determined by annexin, using the V-FITC/PI staining method. Tests were performed in triplicate for each sample, and analyses were performed by FAC-Scan flow cytometry (Becton-Dickinson, San Jose, USA), according to the manufacturer's guidelines.

In vitro migration assays

The migration in vitro assays were performed using 24-well transwell units (Corning, New York, USA) with an 8 - $\mu \mathrm{m}$-pore-size polycarbonate filter. Cells that migrated to the lower surface of the filter were counted under a light microscope at a magnification of $400 \times$, and the number of migratory cells was counted.

Statistical analysis

Data analyses were performed using SPSS 11.0 (SPSS Inc., Chicago, USA).and data were expressed as mean \pm SD. The differences between groups were compared using Student's $t$ test, and differences between populations based on positive or negative IHC results were analyzed by $\chi^{2}$ test, the relationship between BMI1 expression, and clinicpathologic features were also analyzed by $\chi^{2}$ test. All $p$ value $<0.05$ was considered statistically significant.

\section{Results}

BMI1 was over-expressed in bladder cancer tissue than corresponding normal adjacent bladder tissues

BMI1 protein expression was analyzed by Immunohistochemistry. IHC staining showed that $53.5 \%$ (38/71) of bladder cancer tissues were moderately or strongly positive for BMI1 staining, which was expressed in the neoplastic 


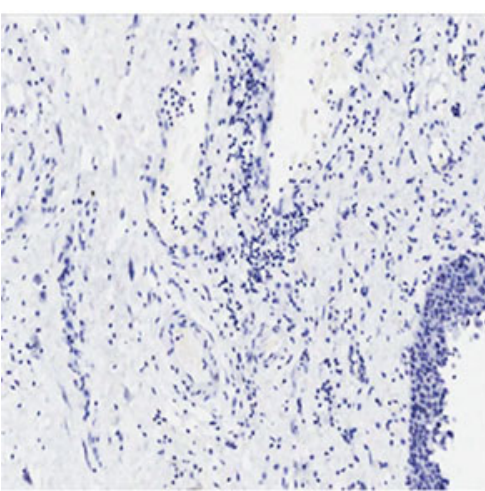

A

Fig. 1 Analysis of BMI1 expression by immunohistochemistry in normal bladder, non-invasive bladder cancer, and invasive bladder cancer tissues. BMI1 expression was localized within the nuclei.

epithelial cell nuclei. This compared with $20.0 \%(7 / 35)$ staining in the adjacent normal tissue samples. $(p<0.05)$ (Fig. 1). And the staining was higher in bladder cancer tissues than the adjacent normal tissues.

BMI1 expression was associated with the clinicpathological features of bladder cancer

The relationship between the clinic-pathological features and the BMI1 expression is shown in Table 2. There was no significantly different between BMI1 protein expression and patients' age and gender and number of tumors. However, the protein expression was significantly, positively associated with, tumor size, clinical stage, and pathological grade.

BMI1 suppressed the expression of p16 and p14 in bladder cancer T24 cells

BMI1 has been proved to suppress the transcription of p16 and p14 in many tumors. To determine whether BMI1 suppresses the expression of p16 and p14 in bladder cancer, we used siRNA to silence BMI1 expression, and then detected the expression of p16 and p14. Western blot showed that p16 and p14 expression was increased after BMI1 knockdown (Fig. 2).

BMI1 knockdown inhibited T24 cells growth and proliferation

To determine the role of BMI1 in cancer cells, we transduced BMI1 siRNA into bladder cancer T24 cells. Then we examined the effect of silencing BMI1 on cell viability using CCK-8 assays. We observed a slight inhibition in growth at 2 days after transduction. Furthermore, obvious inhibitory effects on cell proliferation were observed in

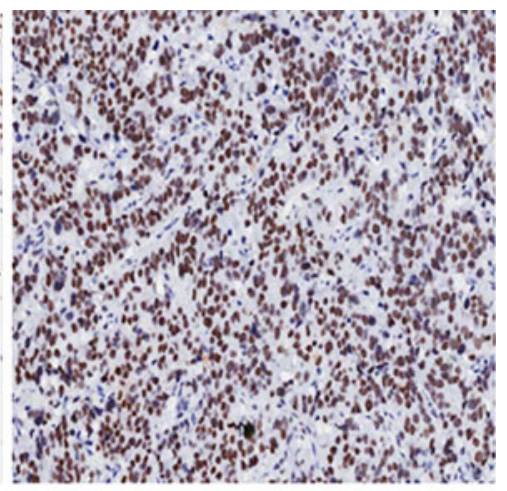

C

a None BMI1 staining in Normal bladder tissue, b moderate staining in non-invasive bladder cancer tissue, $\mathbf{c}$ strong staining in invasive bladder cancer tissue (original magnification $\times 200$ )

BMI1 silenced cells at $3-5$ days (Fig. $3, p<0.05$ ). The soft agar colony formation assay also showed that the numbers of colonies in BMI1 knockdown group was fewer and smaller than the control group (Fig. $4, p<0.05$ ).

BMI1 knockdown prompted T24 cells apoptosis

Flow cytometry showed that a marked increase in apoptosis was observed in BMI1 siRNA group cells, compared to control cells after $48 \mathrm{~h}$ transduction. The ratio of apoptosed cells (Annexin-V+/PI- and Annexin-V+/PI+) in BMI1 depleted cells was significantly higher than in control cells (Fig. 5). WB showed that cell cycle and antiapoptosis related genes cyclin D1, cdk2, Bcl-2 were decreased in BMI1 siRNA group cells than control cells, while apoptosis protein cleaved-caspase 3 was increased (Fig. 6).

BMI1 knockdown decreased T24 cells migration in vitro

Because BMI1 was higher expression in invasive bladder cancer than in non-invasive bladder cancer, we hypothesized that BMI1 regulated the invasive and migration abilities of bladder cancer. To investigate this hypothesis, we measured the effect of BMI1 on T24 cells using an in vitro transwell migration assay. We observed that the number of migrated cells decreased significantly in BMI1 knockdown cells, compared with that of control cells (Fig. 7, $p<0.05$ ).

BMI1 siRNA reduced the migration capacity of T24 cells through EMT change

In our study, we found that the morphology of cells change obviously after BMI1 knockdown. In BMI1 siRNA group 
Table 2 Relationship of BMI-1 protein expression with clinicopathological characteristics of bladder carcinoma

\begin{tabular}{|c|c|c|c|c|c|}
\hline \multirow[t]{2}{*}{ Item } & \multirow[t]{2}{*}{ Cases } & \multicolumn{2}{|c|}{ BMI-1 expression (\%) } & \multirow[t]{2}{*}{$\chi^{2}$} & \multirow[t]{2}{*}{$p$ value } \\
\hline & & Negative & Positive & & \\
\hline Gender & & & & 0.010 & 0.919 \\
\hline Male & 61 & $29(47.5)$ & $32(52.5)$ & & \\
\hline Female & 10 & $4(40.0)$ & $6(60.0)$ & & \\
\hline Age (years) & & & & 0.051 & 0.821 \\
\hline$\leq 50$ & 9 & $5(55.6)$ & $4(44.4)$ & & \\
\hline$>50$ & 62 & $28(45.2)$ & $34(54.8)$ & & \\
\hline Tumor size $(\mathrm{cm})$ & & & & 5.431 & $0.020 *$ \\
\hline$\leq 3$ in diameter & 39 & $23(59.0)$ & $16(41.0)$ & & \\
\hline$>3$ in diameter & 32 & $10(31.3)$ & $22(68.7)$ & & \\
\hline Tumor number & & & & 0.558 & 0.455 \\
\hline Single & 53 & $26(49.1)$ & $27(50.9)$ & & \\
\hline$\geq 2$ & 18 & 7 (38.9) & $11(61.1)$ & & \\
\hline Clinical stage & & & & 17.560 & $p<0.001 *$ \\
\hline Superficial $\left(\mathrm{T}_{\mathrm{is}}, \mathrm{T}_{\mathrm{a}}, \mathrm{T}_{1}\right)$ & 44 & $29(65.9)$ & $15(34.1)$ & & \\
\hline Invasive $\left(\mathrm{T}_{2}, \mathrm{~T}_{3}, \mathrm{~T}_{4}\right)$ & 27 & $4(14.8)$ & $23(85.2)$ & & \\
\hline Pathological grade & & & & 10.036 & $0.007 *$ \\
\hline G1 & 19 & $14(73.7)$ & $5(26.3)$ & & \\
\hline $\mathrm{G} 2$ & 37 & $16(43.2)$ & $21(56.8)$ & & \\
\hline G3 & 15 & $3(20.0)$ & $12(80.0)$ & & \\
\hline
\end{tabular}

* represents statistical significance, $p<0.05$

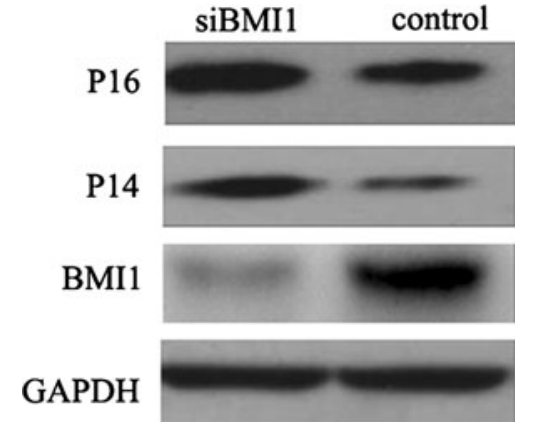

Fig. 2 Effect of BMI1 knockdown on the expression of BMI1, P16, and P14 in bladder cancer T24 cells, measured by western blot. The BMI1 was knockdown by using siRNA transfected. After BMI1 knockdown, the expression of P16 and P14 increased

cells showed cobblestone-like phenotype, whereas the control group cells kept their fibroblastic, elongated like morphology (Fig. 8). To find out whether the effect of BMI1 knockdown on T24 cells migration was associated with EMT, we examined the expression of epithelial marker E-cadherin and mesenchymal marker vimentin by western blot. The result showed that the epithelial marker E-cadherin increased, whereas the mesenchymal marker vimentin decreased in BMI1 siRNA group cells (Fig. 9). These findings suggested that BMI1 increased cells migration maybe through EMT change.

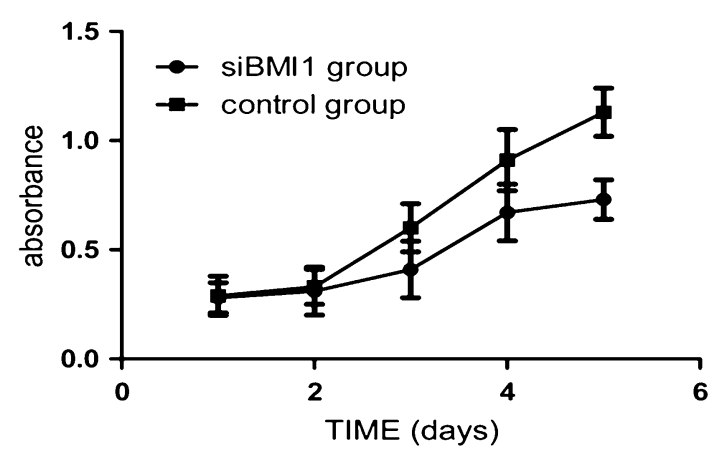

Fig. 3 BMI1 knockdown inhibited the proliferation of T24 cells in vitro. The growth rates in BMI1 knockdown group was significantly reduced than control group, measured by CCK8 assay. The growth curves were determined in triplicate, and they were representative of three independent experiments

\section{Discussion}

In this study, we found that BMI1 was highly expressed in bladder cancer and its expression was correlated with clinic-pathological features. We demonstrated here that BMI1 promoted bladder cancer cell proliferation, migration, and progression by inhibition p16 and p14 expression. Knockdown of endogenous BMI1 expression reduced bladder cancer proliferation and invasiveness.

PcG protein expression is often up-regulated in many types of human cancers. BMI1 is a member of the PRC1 


\section{A}

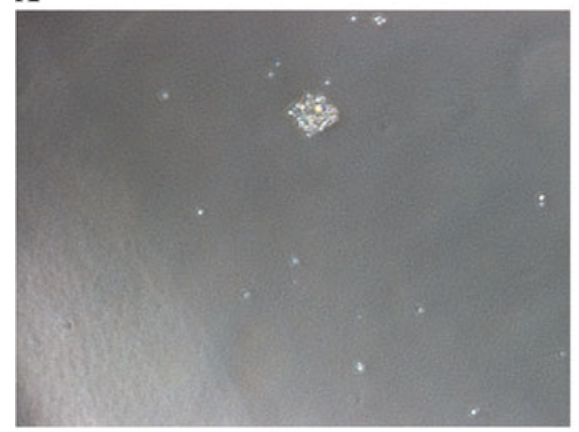

$\mathbf{a}$

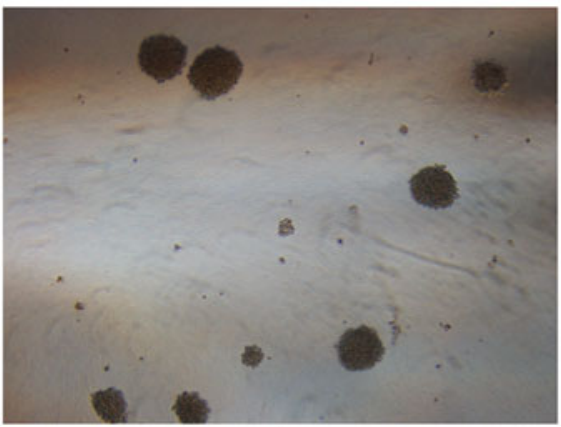

b
B

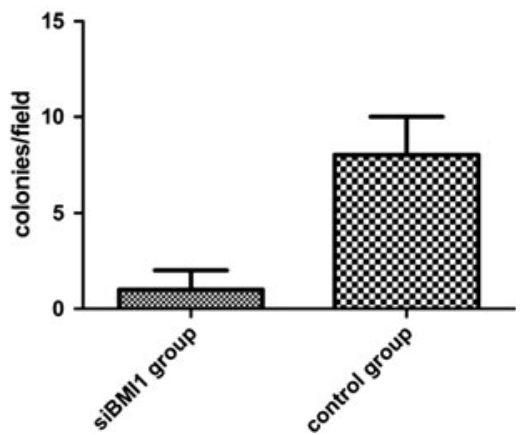

Fig. 4 a Soft agar colony formation assay showed that BMI1 knockdown reduced T24 cell colony formation. Colonies larger than $1 \mathrm{~mm}$ in diameter were counted. The number of T24 colonies was significantly reduced by BMI1 knockdown. (a) BMI1 siRNA group (b) control group. b The bar graph showed the mean number of colonies in 10 low power fields for each group. $p<0.05$, Student $t$ test

A

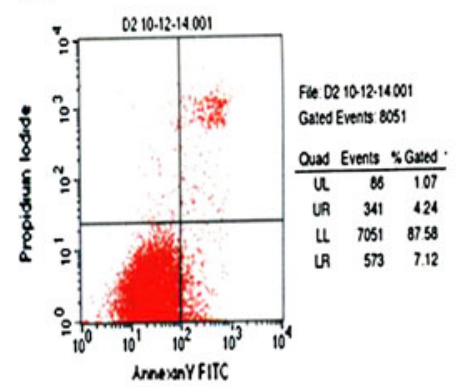

a. siBMI1 group

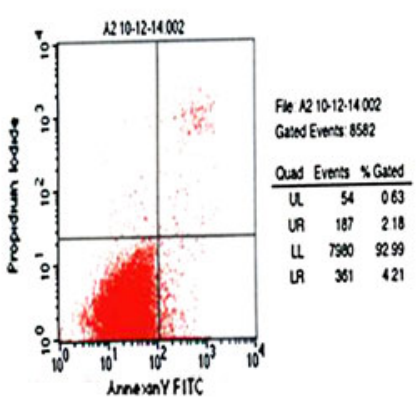

b. control group
Fig. 5 a BMI1 knockdown enhanced the apoptosis of T24 cells. Apoptotic cells of different groups were measured by flow cytometry after $48 \mathrm{~h}$ transduction. The cell populations of Annexin-V +/PIand Annexin- $\mathrm{V}+/ \mathrm{PI}+$ were used to assess apoptotic events.

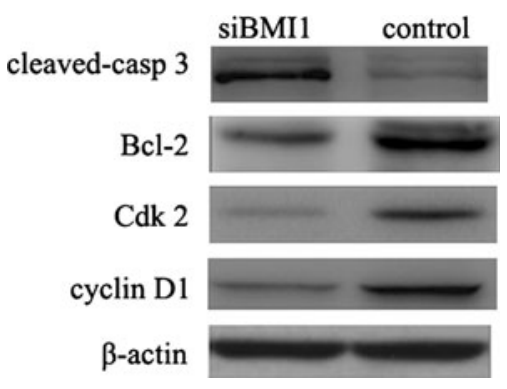

Fig. 6 Effect of BMI1 knockdown on the expression of cell cycle and apoptosis related genes, measured by western blot. Cyclin D1, cdk2, BCL2 were decreased in BMI1 siRNA group cells than control cells, while apoptosis protein cleaved-caspase 3 was increased

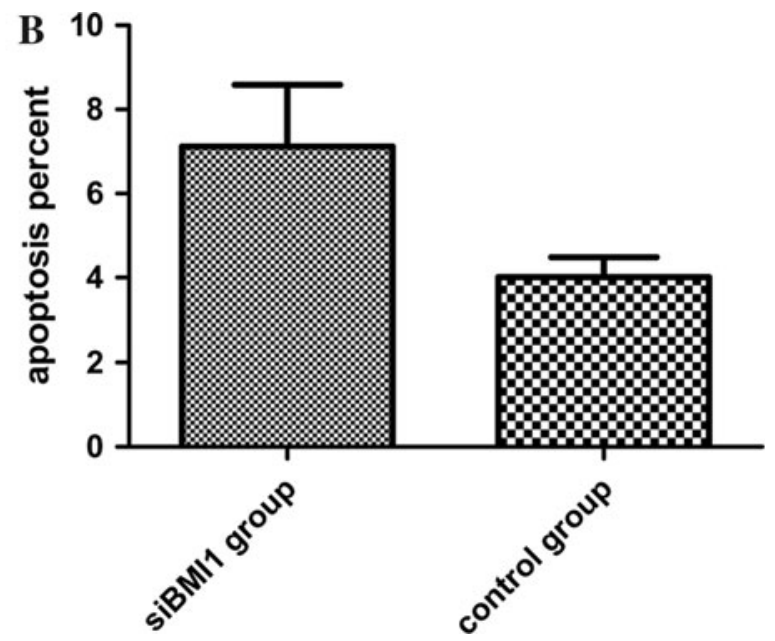

(a) BMI1 siRNA group, (b) control group. b The apoptosis rate of BMI1 siRNA group cells was significantly higher than that of control group cells. $p<0.05$, Student $t$ test

complex; it controls many diverse biological cancer processes including differentiation, senescence, proliferation, migration, and tumorigenesis [15]. Much evidence have linked BMI1 to aggressive, malignant behavior, and poor clinical outcome in various cancer cells, including prostate cancer, breast cancer, lung cancer, ovarian cancer, and hepatocellular cancer [16-19]. Regarding the relationship between BMI1 expression and bladder cancer clinicpathology, there are very few reports about their relationship. A prior study found that BMI1 was highly expressed in bladder cancer, and served as a prognostic marker in bladder cancer, supporting our results on BMI1 expression in bladder cancer [11]. However, they are unclear as to the 
$\mathbf{A}$

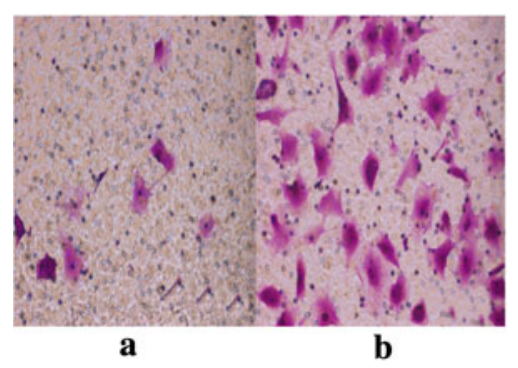

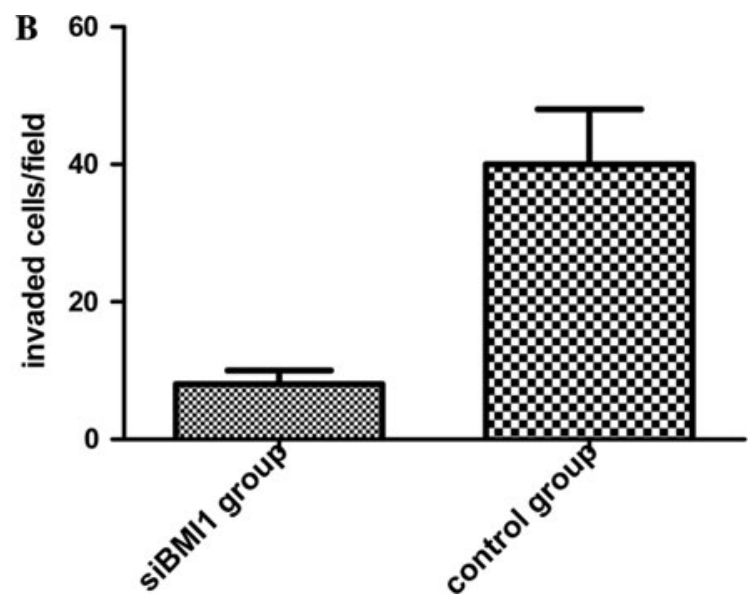

than that of the BMI1 siRNA group. (a) BMI1 siRNA group, (b) control group. b Quantification of the numbers of BMI1 siRNA group and control group cells migrating through the matrigel. $p<0.05$, Student $t$ test

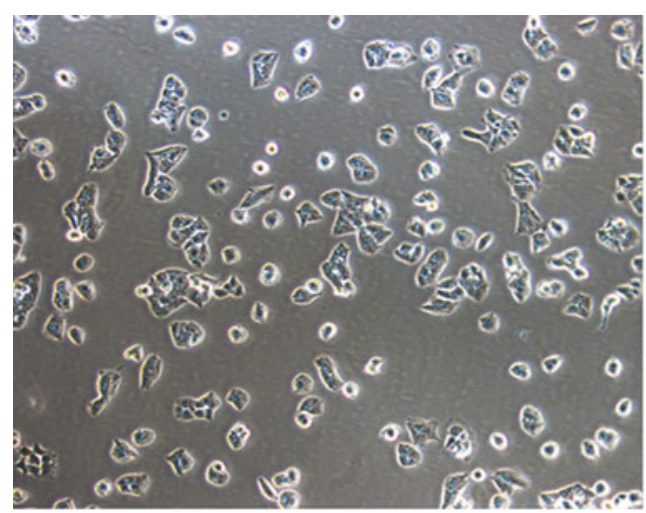

A

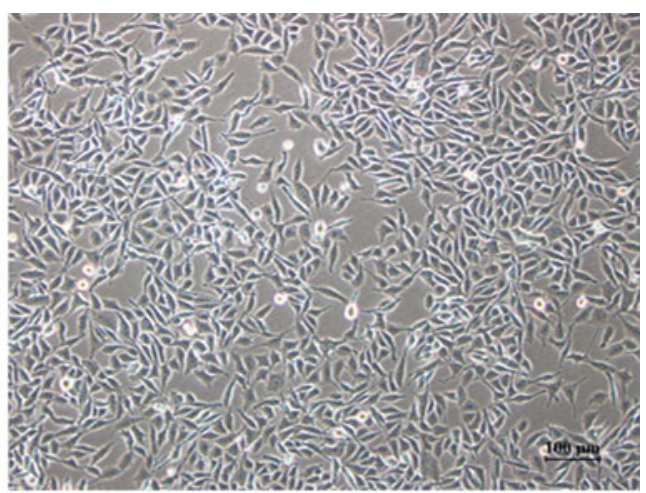

B
Fig. 8 Morphologic changes in T24 cells after BMI1 knockdown. a BMI1 siRNA group, b control group. In the BMI1 siRNA group, cells showed cobblestone-like morphology, whereas the control group

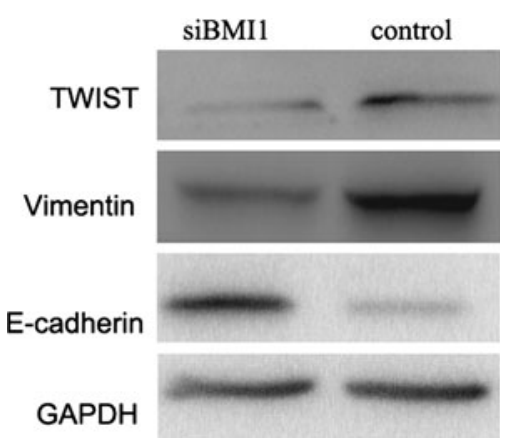

Fig. 9 Effect of BMI1 knockdown on the expression of epithelial marker E-cadherin and mesenchymal marker vimentin and twist, measured by western blot. The epithelial marker E-cadherin was increased, whereas the mesenchymal marker vimentin and twist decreased in BMI1 siRNA group cells than control group cells cells kept their fibroblastic, elongated like morphology. Photos were taken under $\times 200$ magnification

molecular mechanism of how BMI1 influences bladder cancer development, how BMI1 promotes bladder cancer proliferation and migration. It has been proved that ink-14arf is the downstream target of BMI1, which encodes two tumor suppressor proteins, p16 and p14. The p16-pRb pathway and p53-p14 pathway are two tumor suppressor pathways that are inactivated in many cancers [20-23].

Over-expression of BMI1 or deletions of p16 and p14 are frequently discovered in many cancers, but their roles in bladder cancer have not been previously recognized. We have demonstrated here, that by using siRNA to silence BMI1 expression, the p16 and p14 expression are increased, which in turn inhibited cell growth in bladder cancer. These results suggested that BMI1 promoted bladder cancer proliferation by inhibiting the p16-pRB and p53-p14 pathways. These results were similar to studies 
performed on other cancers that BMI1 promoted cancer cell proliferation through inhibition of ink-14-arf locus expression. However, it was also well known that BMI1 modulated the DDR pathway and PI3K/AKT pathway that then caused cancer cell progression [24, 25]. So, the precise molecular mechanism of BMI1 in the tumorigenesis and proliferation of bladder cancer needs to be further explored.

Additionally, it was reported that BMI1 was involved in the metastasis of cancers. Over-expression of BMI1 was associated with increased risk of metastasis [26, 27]. Here, our results indicated that BMI1 expression displayed correlation with the clinic-pathological features of the bladder cancers, and BMI1 expression in invasive bladder cancer was significantly higher than that in superficial bladder cancer. Furthermore, BMI1 siRNA in bladder cancer T24 cells reduced the migration of bladder cancer in vitro. These results provided powerful evidence that silencing BMI1 expression contributed to a reduction in the migration of bladder cancer, and suggested that BMI1 was significantly associated with the metastatic ability of bladder cancer.

Epithelial-to-mesenchymal transition is a process by which cancer cells change their epithelial phenotype into a mesenchymal phenotype and acquire metastatic ability, which is closely associated with the invasive and metastatic process of cancers [28]. Many reports have addressed the association between BMI1 and EMT. A study has shown that BMI1 inhibited the expression of PTEN, and modulated PI3K/AKT/GSK-3b/snail signaling, which promotes EMT and enhances the metastatic ability of nasopharyngeal cancer cells [25]. Another study demonstrated that twist1 regulated BMI1 expression, which then resulted in the occurrence of EMT and cancer stem cell characteristics [29]. In our study, Consistent with the reduced metastatic behavior of these cancer cells, the epithelial marker E-cadherin increased in BMI1 siRNA group cells, whereas the mesenchymal marker vimentin and twist decreased. Combined with our study, all these supported the idea that BMI1 promoted the invasion and migration of bladder cancer maybe through acquiring EMT characteristics. However, the exact mechanism requires further investigation.

In conclusion, our results have demonstrated that BMI1 promoted proliferation, migration, invasion, and progression in bladder cancer. Over-expression of BMI1 was correlated with tumor clinic-pathological features. BMI1 siRNA effectively inhibited bladder cancer cell proliferation and migration in vitro, and it promoted bladder cancer invasion, maybe by causing EMT. Our findings suggest that BMI1 may represent a novel diagnostic marker and a therapeutic target for bladder cancer, and deserves further investigation.
Acknowledgments This study was supported by a Grant from National Natural Science Foundation of China (No. 81072102 to WL $\mathrm{Xie)}$.

Conflict of interest All authors declare no conflict of interest.

Open Access This article is distributed under the terms of the Creative Commons Attribution License which permits any use, distribution, and reproduction in any medium, provided the original author(s) and the source are credited.

\section{References}

1. Efstathiou JA, Spiegel DY, Shipley WU, Heney NM, Kaufman DS, Niemierko A, Coen JJ, Skowronski RY, Paly JJ, McGovern FJ, Zietman AL (2012) Long-term outcomes of selective bladder preservation by combined-modality therapy for invasive bladder cancer: the MGH experience. Eur Urol 61(4): 705-711

2. Park IK, Morrison SJ, Clarke MF (2004) BMI1, stem cells, and senescence regulation. J Clin Invest 113:175-179

3. Jacobs JJ, van Lohuizen M (2002) Polycomb repression: from cellular memory to cellular proliferation and cancer. Biochim Biophys Acta 1602:151-156

4. van Lohuizen M, Verbeek S, Scheijen B et al (1991) Identification of cooperating oncogenes in E mu-myc transgenic mice by provirus tagging. Cell 65(5):737-752

5. Wang H, Pan K, Zhang HK, Weng DS, Zhou J, Li JJ, Huang W, Song HF, Chen MS, Xia JC (2008) Increased polycomb-group oncogene BMI-1 expression correlates with poor prognosis in hepatocellular carcinoma. J Cancer Res Clin Oncol 134(5):535541

6. Honig A, Weidler C, Häusler S, Krockenberger M, Buchholz S, Köster F, Segerer SE, Dietl J, Engel JB (2010) Overexpression of polycomb protein BMI-1 in human specimens of breast, ovarian, endometrial and cervical cancer. Anticancer Res 30(5):15591564

7. Song LB, Zeng MS, Liao WT, Zhang L, Mo HY, Liu WL, Shao JY, Wu QL, Li MZ, Xia YF, Fu LW, Huang WL, Dimri GP, Band V, Zeng YX (2006) BMI-1 is a novel molecular marker of nasopharyngeal carcinoma progression and immortalizes primary human nasopharyngeal epithelial cells. Cancer Res 66(12):62256232

8. Godlewski J, Nowicki MO, Bronisz A, Williams S, Otsuki A, Nuovo G, Raychaudhury A, Newton HB, Chiocca EA, Lawler S (2008) Targeting of the BMI-1 oncogene/stem cell renewal factor by microRNA-128 inhibits glioma proliferation and self-renewal. Cancer Res 68(22):9125-9130

9. Kimura M, Takenobu H, Akita N, Nakazawa A, Ochiai H, Shimozato O, Fujimura Y, Koseki H, Yoshino I, Kimura H, Nakagawara A, Kamijo T (2011) BMI1 regulates cell fate via tumor suppressor WWOX repression in small-cell lung cancer cells. Cancer Sci 102(5):983-990

10. Itahana K, Dimri GP (2010) Can BMI-1 be a biomarker of poor prognosis? Epigenomics 2(5):609-610

11. Qin ZK, Yang JA, Ye YL, Zhang X, Xu LH, Zhou FJ, Han H, Liu ZW, Song LB, Zeng MS (2009) Expression of BMI-1 is a prognostic marker in bladder cancer. BMC Cancer 19(9):61

12. Tagawa M, Sakamoto T, Shigemoto K, Matsubara H, Tamura Y, Ito T et al (1990) Expression of novel DNA-binding protein with zinc finger structure in various tumor cells. J Biol Chem 265(32):20021-20026 
13. Goebl MG (1991) The BMI-1 and MEL-18 gene products define a new family of DNA-binding proteins involved in cell proliferation and tumorigenesis. Cell 66(4):623

14. Xu Z, Liu H, Lv X, Liu Y, Li S, Li H (2011) Knockdown of the BMI-1 oncogene inhibits cell proliferation and induces cell apoptosis and is involved in the decrease of Akt phosphorylation in the human breast carcinoma cell line MCF-7. Oncol Rep 2:409-418

15. Pasini D, Bracken AP, Helin K (2004) Polycomb group proteins in cell cycle progression and cancer. Cell Cycle 3:396-400

16. Fan C, He L, Kapoor A, Gillis A, Rybak AP, Cutz JC, Tang D (2008) BMI1 promotes prostate tumorigenesis via inhibiting p16(INK4A) and p14(ARF) expression. Biochim Biophys Acta 1782(11):642-648

17. Riis ML, Lüders T, Nesbakken AJ, Vollan HS, Kristensen V, Bukholm IR (2010) Expression of BMI-1 and MEL-18 in breast tissue-a diagnostic marker in patients with breast cancer. BMC Cancer 10:686

18. Vrzalikova K, Skarda J, Ehrmann J, Murray PG, Fridman E, Kopolovic J, Knizetova P, Hajduch M, Klein J, Kolek V, Radova L, Kolar Z (2008) Prognostic value of BMI-1 oncoprotein expression in NSCLC patients: a tissue microarray study. J Cancer Res Clin Oncol 134(9):1037-1042

19. Yang GF, He WP, Cai MY, He LR, Luo JH, Deng HX, Guan XY, Zeng MS, Zeng YX, Xie D (2010) Intensive expression of BMI-1 is a new independent predictor of poor outcome in patients with ovarian carcinoma. BMC Cancer 10:133

20. Jacobs JJL, Kieboom K, Marino S, DePinho RA, van Lohuizen M (1999) The oncogene and polycomb-group gene BMI-1 regulates cell proliferation and senescence through the ink4a locus. Nature 397:164-168

21. Sharpless NE, DePinho RA (1999) The INK4A/ARF locus and its two gene products. Curr Opin Genet Dev 9:22-30
22. Kim JH, Yoon SY, Kim CN, Joo JH, Moon SK, Choe IS, Choe YK, Kim JW (2004) The BMI-1 oncoprotein is overexpressed in human colorectal cancer and correlates with the reduced p16INK4a/p14ARF proteins. Cancer Lett 203(2):217-224

23. Vonlanthen S, Heighway J, Altermatt HJ et al (2001) the BMI-1 oncoprotein is differentially expressed in non-small cell lung cancer and correlates with INK4A-ARF locus expression. Br J Cancer 84:1372-1376

24. Ismail IH, Gagné JP, Caron MC, McDonald D, Xu Z, Masson JY, Poirier GG, Hendzel MJ (2012) CBX4-mediated SUMO modification regulates BMI1 recruitment at sites of DNA damage. Nucleic Acids Res 40(12):5497-5510

25. Song LB, Li J, Liao WT, Feng Y, Yu CP, Hu LJ, Kong QL, Xu LH, Zhang X, Liu WL, Li MZ, Zhang L, Kang TB, Fu LW, Huang WL, Xia YF, Tsao SW, Li M, Band V, Band H, Shi QH, Zeng YX, Zeng MS (2009) The polycomb group protein BMI-1 represses the tumor suppressor PTEN and induces epithelialmesenchymal transition in human nasopharyngeal epithelial cells. J Clin Invest 119(12):3626-3636

26. Guo BH, Feng Y, Zhang R, Xu LH, Li MZ, Kung HF, Song LB, Zeng MS (2011) BMI-1 promotes invasion and metastasis, and its elevated expression is correlated with an advanced stage of breast cancer. Mol Cancer 10(1):10

27. Song W, Tao K, Li H, Jin C, Song Z, Li J, Shi H, Li X, Dang Z, Dou K (2010) BMI-1 is related to proliferation, survival and poor prognosis in pancreatic cancer. Cancer Sci 101(7):1754-1760

28. Gomes LR, Terra LF, Sogayar MC, Labriola L (2011) Epithelialmesenchymal transition: implications in cancer progression and metastasis. Curr Pharm Biotechnol 12(11):1881-1890

29. Yang MH, Hsu DS, Wang HW, Wang HJ, Lan HY, Yang WH, Huang CH, Kao SY, Tzeng CH, Tai SK, Chang SY, Lee OK, Wu KJ (2010) BMI1 is essential in Twist1-induced epithelial-mesenchymal transition. Nat Cell Biol 12(10):982-992 